\title{
Measuring the Impact of Risk on Bank Spreads in Commercial Banks in Kenya
}

\author{
Jane Isiaho $^{1^{*}}$ Prof. Lucky Yona ${ }^{2}$ \\ 1.PHD student, Swiss School of Management \\ 2.Eastern and Southern African Institute of Management
}

\begin{abstract}
This study looks at the impact of risk on bank spreads in Kenya's banking sector using data from 13 banks selected through purposive sampling on the basis of available data. Two forms of risk namely credit risk and liquidity risk are analysed against bank spread as dependent variable. Bank spread is measured in two ways: interest rate spread and gross margin. The data is analysed using correlation and regression statistics. The findings on credit risk are non-significant and not in the expected direction of the study hypothesis. Liquidity risk results were negative and significant with both spread measures leading to the conclusion that banks recover the opportunity cost of holding low earning assets from customers. There is need for banks to come up with more innovative investment products for its depositors to allow for longer term holding of such deposits thus lowering liquidity risk premiums. Government would also do well to manage the level of borrowing from the domestic market so as to re-direct commercial bank lending away from the low earning government paper to private lending which has higher yields. This would reduce the need to cover for the opportunity cost of holding so much assets in liquid form.
\end{abstract}

Keywords: Credit risk, liquidity risk, bank spread

DOI: $10.7176 /$ RJFA/12-10-09

Publication date:May $31^{\text {st }} 2021$

\section{Introduction}

Interest rate spread is defined as the difference between bank lending and deposit rates (Georgievska, et al, 2011), and is an indicator of the cost and efficiency of financial intermediation. A wide interest spread tends to stifle economic growth in the sense that low rates on deposits discourage savers hence denying the intermediary the availability of funds to lend out. At the same time, high rates on loans may make the loans unaffordable for borrowers hence limiting investment activities (Ndungu \& Ngugi, 2000). This is especially so in growing economies like Kenya where the financial market is under-developed and the economy depends on banks almost exclusively as a source of finance. Financial regulators are faced with the challenge of balancing financial stability and growth. Too much focus on ensuring a strong and stable financial sector can stifle growth whereas attaining too fast a growth may lead to future financial crisis. Regulators must therefore aim to strike a balance between ensuring bank interest spreads are sufficient to maintain a stable financial system and at the same time low enough to facilitate access to finance in order to attain economic growth.

Various theories have been advanced to explain the determination of bank spreads and the factors that influence the same. The Ho and Saunders' dealership model, deemed to be the foundational model for the determination of bank interest margins, integrates and extends the hedging hypothesis and the banking firm models (Ho \& Saunders, 1981). Under this integrated model, the bank is viewed as a dealer in the deposits and loans market. The bank, in its dealership is faced with a funding or re-investment risk arising from the noncontemporaneous arrival times of loans and deposits. If a loan demand arrives before there is a deposit supply, the bank will have to borrow from the money market to fund the loan demand thus facing a refinancing risk should the money market rates rise. Similarly, if a deposit supply arrives when there is no loan demand, the bank will need to invest the surplus money in the money markets thus facing a reinvestment risk should money market rates fall. To secure a positive return therefore, the bank needs to make loans at a rate higher than the money market rates to cover for the refinance risk. At the same time it needs to accept deposits at a rate lower than the money market rates to cover for the re-investment risk (Maudos \& Fernández De Guevara, 2004). Subsequent empirical studies have identified various other sources of risk such as credit and liquidity risks (Valverde \& Fernandez, 2007).

\section{Research problem}

With a less developed financial system, banks remain the main source of finance for economic development. (Koffie et al, 2014). Financial reforms and liberalization are expected to narrow interest rate spreads by increasing efficiency and competitiveness in the banking industry. To achieve this, Kenya has been on a series of sustained financial liberalization and reforms since the early 1990s.

Interest rate spread in Kenya remains high at 9.21\% (CBK Statistical Bulletin, 2015b) in 2015 as compared to the world's average of 5.3\% (Appendix table A 1). Kenya has put in place so many interventions to try and address this wide spread since the interest rate liberalization in 1991 but the spread has not been contained at 
acceptable levels. Interest rate spreads still remain high and prohibitive of access to credit in Kenya and there is need for an in-depth study of its main drivers. Credit risk as measured by the rate of non-performing debts has been persistently high in Kenya with the ratio remaining above 10 in all but one of the years under review (appendix table 2). Liquidity is an important indicator of financial stability as its shortfall in one bank can cause a crisis in the sector due to their closely related operations. Though the average liquidity ratios have remained high over the period under review, some banks have had to be shut down owing to liquidity challenges. Indeed liquidity and credit risks have remained important areas of concern in the banking sector (CBK, 2018). Given their theoretical association with bank spread, this study will assess the impact of these risks on bank spread in Kenya during the period from 2009 to 2018. This study is particularly important in Kenya where there has been a lingering perception that interest spreads charged by commercial banks are too high and inhibitive of access to finance.

\section{Literature review}

\subsection{Credit risk}

The earliest extensions of the dealership model of interest rate spread acknowledge the role played by credit risk in the determination of interest rate spread. Many scholars have subsequently measured the effect of this on interest rate determination in various different scholarly works. Credit risk is commonly measured by the ratio of nonperforming loans to total loans. The high incidence of loans default leads to higher provisions and given that banks are risk averse, they are likely to charge a higher risk premium on loans to cover for the possible losses leading to higher spread (Were \& Wambua, 2013). Achille Fofack, found credit risk to be positive and significant in determining interest rate spread in his study of the Central African Economic and Monetary Community member countries. This is attributed to the banks' behaviour of charging higher premiums in response to higher cases of default (Fofack, 2016). Manasoo(2012) finds the same result for Estonian banks though in this case, the share of credit risk in spread composition is surprisingly low, a possible indication that banks in Estonia manage a bigger part of its risk exposure by increasing capital buffers rather than relying on risk based pricing systems.(Männasoo, 2012). Koffie et al. (2014) in their study of interest margins in Honduras also found significant and positive correlation between interest margin and credit risk, an indication that increased credit risk does prompt banks to increase their interest rates. Rusuhuzwa et al. (2016) agrees with this notion that banks increase interest rates as credit risk increases in his study of interest rate spread determinants in Rwanda. He recommends use of credit reference bureaus to reduce information asymmetry and mitigate credit risk (Rusuhuzwa \& Karangwa, Mathias; Nyalihama, 2016). Romero and Rodriquez (2011) in their study of interest rate spread in Costa Rica agree with the above findings and conclude that banks tend to pass on to customers the cost of lost incomes that results from default. (Romero, Jose Pablo Barquero; Rodriguez, 2011)

Perez (2011) studied the determinants of interest rate spread in Belize using the accounting decomposition method as well as the dynamic ordinary least squares statistical method. The study covering the period from 2001 to 2009 identified non-performing loans and market share to be major determinants of interest rate spread in Belize. The econometric model finds a positive relationship between market share and interest rate spread indicative of a market structure that allows banks to pass on increasing costs directly to the customer by way of wider spreads. This ability to pass on costs is also reflected in non-performing loans where though the ratio increased over the period under study, profit after tax still accounted for around $20 \%$ of spread. The study suggests that to reduce non- performing debts, banks need to accurately assess creditworthiness of their clients and charge different lending rates to consumers based on their credit risk. This would eliminate the need to increase interest on performing loans to compensate for non-performing ones. According to both the accounting and econometric models, non-interest income significantly reduces spread. Increased fee-based activities may have compensated for inefficiency having sufficiently covered the increasing costs in the period under review. Higher concentration of time deposits reduces spread owing to customers being able to negotiate higher than average deposit rates. The accounting method also shows profit after tax and operating expenses as the largest components of interest rate spread. The study recommends increased competition, reduced information asymmetry and a comprehensive consumer protection policy for financial services as a solution to tame interest rate spread.

Banks will tend to respond to risks by adding a risk premium to the lending rates resulting in wider margins. Credit risk, proxied by the ratio of loans to total assets, though found to be positive, was insignificant according to Khediri and Ben-Khedhiri, (2011) in their study of net interest margins in Tunisia. This result may be partly influenced by the fact that the ratio of loans to total assets may not be the best proxy for credit risk. A better proxy would be the coverage ratio as measured by loan loss provisions to non-performing loans ratio or the nonperforming loans rate measured by non-performing loans to total loans ratio. Increase in doubtful loans was found to be positively related to margins possibly because doubtful loans are an indicator of the level of uncertainty surrounding lending prompting banks to charge higher premiums (Fofack, 2016) Provisions on non-performing loans, credit-to - deposit ratio and liquidity ratio are significant and positively related to net interest margins (Koffie et al., 2014).

Interestingly, some scholars have found a negative relationship between interest rate spread and credit risk 
contrary to theoretical expectation. In their study of factors influencing interest spread in Iranian banks, Ghasemi and Rostami (2015) found a significant and negative correlation between the ratio of non-performing loans and spread. According to the study, a $1 \%$ increase in non-performing loans leads to a $0.97 \%$ reduction in spread (Ghasemi \& Rostami, 2015) This finding is explained by the fact that when non-current loans increase, interest income reduces as interest on non-performing loans is reserved. This has the effect of reducing interest spread as calculated in this study. Georgievska et al. (2011) finds that credit risk has a prolonged effect on interest margins. In their study they find that credit risk is significant and positive only on the fourth leg of the periods under review.

\subsection{Liquidity risk}

Liquidity risk is defined as the risk that a bank will not be able to meet the cash withdrawal needs of its customers as well as make new loans. Banks with higher proportions of liquid assets in their balance sheet face lower liquidity risks and therefore do not need to apply high liquidity risk premiums on their rates. Banks with high liquidity risk are forced to make emergency borrowing at high costs to cover their cash withdrawal and new loan demands. To cover for such costs, the banks will charge wide spreads on their rates (Ahokpossi, 2013). In empirical research, liquidity risk is often proxied by the ratio of liquid assets to total assets (Were \& Wambua, 2013; Ugur \& Erkus, 2010; Koffie et al., 2014; Gounder \& Sharma, 2012). As the proportion of liquid assets increases, liquidity risk decreases and so does the liquidity premium required. Lower liquidity ratios correspond with higher liquidity risk.

In the study based on Sub-Saharan Africa, Ahokpossi (2013) found liquidity ratio to have a negative and significant relationship with spread pointing to the need for banks with low liquidity to borrow at high costs to meet their liquidity needs. Were and Wambua (2013), found similar results for the case of Kenya reflecting the possibility that Kenyan banks were paying a higher premium for deposits in order to maintain the required liquidity ratios given the quick loan mobilization. Nassar et al's views on liquidity risk are different from the above. According to them, higher liquidity may indeed result in lower liquidity risk. Liquid assets are composed of cash and near cash investments which often have very low yields or none at all in the case of cash. Koffie et al. (2014) argue that the opportunity cost that comes with holding high levels of liquid assets may lead banks to charge higher interest spread in order to compensate for the lost incomes in which case higher liquidity ratios would have a positive impact on spread. Their study indeed found a positive and significant association though with a small coefficient.

\subsection{Bank spread}

There are two common approaches to the calculation of interest rate spread in empirical studies. The first is termed as the ex-ante spread and is the difference between the actual lending rate and deposit rate as per contract with customers. These rates are in the public domain and easily observable in actual rates in the market. The second one is termed as ex-post spread and is the difference between the average realised interest income and average realised interest expense. The average interest income is calculated as total interest income received divided by the average stock of loans and advances while the average interest expense is arrived at by dividing the interest expense by the average stock of total deposits. Whereas the ex-ante spread is the most direct indicator of the actual difference between lending and deposit rates, it is not always easy to get bank level data on the same. Besides, banks charge different lending rates for different product categories and different lending durations. Customers and their businesses also carry different risk profiles and are likely to be charged interest in accordance to their respective risk classes. Deposits also attract different interest rates according to the term and the total relationship value of individual customers. For this reason, it is difficult to find a singular way of measuring the difference between lending and deposit rates (Gounder \& Sharma, 2012). As a result of this, scholars have come up with different ex-post indicators to measure interest rate spread.

Our current study will be based on bank level data and for that reason will employ the ex-post spread which uses the ratio of interest income to average loans minus the ratio of interest expense to average deposits (Konar, 2014). This approach to calculating spread as explained earlier also controls for fluctuations in loans and deposits throughout the year. The second spread measure we employ for this study is gross margin measure derived as the ratio of total income to total assets to reflect the effect of non-traditional activities undertaken by the banks (Valverde \& Fernández, 2007).

\section{Conceptual framework}

Figure 1 below depicts our conceptualization of the relationship between risk and bank spread. Both credit and liquidity risks have a direct influence on banks spreads. This association will be examined through correlation and regression analysis. 
Figure 1 Conceptual framework Independent Variables

\section{Dependent Variable}

\begin{tabular}{|c|c|c|}
\hline $\begin{aligned} \text { Risk } & \\
\text { - } & \text { Credit risk } \\
\text { - } & \text { Liquidity risk }\end{aligned}$ & 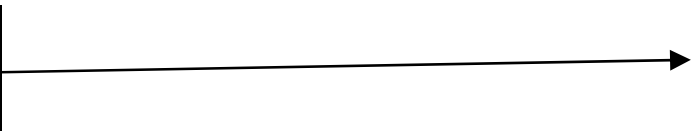 & $\begin{aligned} & \text { Bank spread } \\
& \text { - } \text { Interest rate spread } \\
& \text { - } \text { Gross margin } \\
&\end{aligned}$ \\
\hline
\end{tabular}

\subsection{Independent variables}

Risk

The variables that will be measured under risk are credit risk (CR) and liquidity risk (LR). Risks have the potential to reduce a bank's ability to generate income as a result of which banks generally hedge their exposure to risk by charging higher margins (Fofack, 2016). Inherent in the making of loans is the probability of a loan default in part or the whole. Consequent to this, banks include a risk premium in their lending interest setting to cover for the cost of such possible loss resulting in wider spreads. In their study of the factors explaining interest margins in the European Union, Maudos and Guevara (2004), found that credit risk has a positive relationship to net interest margins. Credit risk has been measured as the ratio of non-performing loans to total loans and advances by Rebei (2014) and Raharjo et al. (2014). Non-performing loans give rise to additional costs in terms of provisions which banks tend to pass on to customers. In this study credit risk is proxied by non-performing loans ratio calculated as shown below:

$\mathrm{CR}=\frac{N P L_{i, t}}{T L_{i, t}}$

Where, $N P L$ is the non-performing loan value of bank $i$ at time $t$ and $T L$ is total loans of bank $i$ at time $t$ (Rebei, 2014; Raharjo et al., 2014).

We hypothesize that banks set higher risk premiums when the exposure to credit risk is higher thus leading to wider spread. A positive relationship is therefore expected between credit risk and bank spread.

Liquidity risk is the probability that the bank might have insufficient cash to meet new loan demand or deposit withdrawals by customers. Liquidity risk decreases with increase in the proportion of liquid assets. This is expected to decrease the liquidity premium charged and therefore reduce interest spread. Liquidity risk is proxied by liquidity ratio calculated as the ratio of liquid assets to deposits.

$\mathrm{LR}=\frac{L A_{i, t}}{D_{i, t}}$

Where LR is the liquidity ratio, LA is liquid assets of bank $i$ at time $t$ and $\mathrm{D}$ is the deposits of bank $i$ time $t$ (Ahokpossi, 2013).

Liquidity risk increases as the ratio decreases. Higher liquidity ratios correspond to lower risks and banks in such a situation are expected to charge lower risk premiums leading to lower bank spread (Ahokpossi, 2013; Fofack 2016). Liquidity risk is expected to have a positive effect on bank spread since faced with high liquidity risk, banks will source emergency funding at high costs which in turn are recovered through high liquidity premium on loans. The following hypotheses are formulated:

H1: There is a positive relationship between risk and bank spread.

This hypothesis was tested along with two minor hypotheses:

H1a: There is a positive relationship between credit risk and bank spread.

H1b: There is a positive relationship between liquidity risk and bank spread.

\subsection{Dependent variable}

The ex-post spread is used more commonly in studies of interest spreads that employ bank-level data due to readily available data as compared to ex-ante spread. The ex-post spread also controls for the fact that banks with high yields and risky credits are likely to face more defaults. Loans and deposits are not at the same level throughout the year. To achieve a more accurate ratio, this study will be using the ex-post interest spread calculated as shown below (Giordano \& Lopez, 2015).

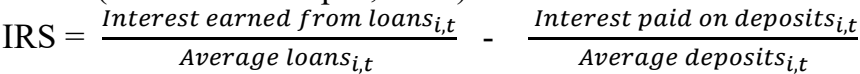

Where $i$ is the individual bank and $t$ the respective year.

This study also employs a second measure of spread that includes non- interest income to take into account the diversification effect. The calculation for this measure are shown below:

GRNIM $=\frac{\text { Total }_{\text {income }}, t}{\text { Total } \text { assets }_{i, t}}$

Where $i$ is the individual bank and $t$ the respective year. 


\section{Methodology}

This study uses secondary data collected from 13 commercial banks in Kenya that were in active business in the period 2009 to 2018 . The selection process was through purposive sampling in order to determine the banks with complete required data for the period. The data was obtained from the selected banks' financial reports and the same analysed in panel data. Statistical analysis was done with the help of SPSS and STATA softwares. The thirteen banks selected jointly hold $70 \%, 78 \%$ and $72 \%$ of the industry's assets, loans and deposits respectively.

\subsection{Data reliability and validity}

For the multiple regression equation to yield reliable results, the following assumptions must be satisfied: The existence of a normal distribution and linear relationship, absence of multicollinearity, auto-correlation and heteroscedasticity. The presence of outliers was tested by use of boxplots and the results presented in appendix figure A 1. The three entries noted to be outliers related to actual occurrences in the non-performing loans ratio of the respective banks so the same could not be amended. The same is not expected to affect the results as this analysis will use a robust regression analysis estimator. The relationship for liquidity risk with both dependent variables is evidently linear. The depiction is not as clear for credit risk although the P-P Plots for both independent variables show that all points fall along a straight line indicative of a linear relationship between the dependent variable and the independent variables (appendix figures A 1). The data for this study passed the normality test with a non-significant Shapiro Wilk test for both spread measures as shown in table 1 below. The value inflation factors used to detect multicollinearity for both variables are below 3.0 and therefore capable of producing reliable results. The correlations coefficients are all below 0.7 and above 0.3 for liquidity ratio. The coefficients for credit risk are below 0.3 though this is not expected to affect the reliability of results significantly as this study employs a robust estimator. The Durbin-Watson statistic was used to detect the presence of autocorrelation and below are the results which reveal that indeed the data suffers autocorrelation problems (table 1). The Durbin-Watson measure in both instances is way below 2 signifying presence of autocorrelation.

One of the assumptions of multiple linear regression is the presence of homoscedasticity. This is a situation where the random disturbance or error term in the relationship of the predicted and predictor variables is the same in all the predictor variable values. The absence of this is a situation known as heteroscedasticity and is a violation that increases the chances of errors in hypothesis testing. This was tested by plotting standardized residuals against standardized predicted values on a scatter plot diagram. Where the variances are homogenous, the plotted residuals against predictor variables should leave a rectangular shaped scatter diagram. In this case the resulting scatter plot diagram was not rectangular in shape (appendix figure A 1) and therefore we conclude the presence of heteroscedasticity which must be addressed to obtain reliable research conclusions. When the autocorrelation and heteroscedasticity assumptions are violated there is a high likelihood of committing a type one error. This situation is mitigated by use of a robust estimator in the regression analysis. This study will adopt the Panel Corrected Standard Error (PCSE) estimator to ensure robustness of regression results and hypothesis testing. Similar studies done by Rebei (2014) and Koffie et al. (2014) have also employed the same estimation technique because of its ability to yield reliable results.

Table 1 Validity tests

\begin{tabular}{llll}
\hline Multicollinearity tests & & & \\
& VIF & \multicolumn{2}{l}{ Pearson Correlation coefficients } \\
& & IRS & GRNIM \\
CR & 1.015 & -0.058 & -0.143 \\
LR & 1.015 & $0.527^{* *}$ & $0.467^{* *}$ \\
\hline Autocorrelation tests & & Normality tests & \\
\hline & Durbin Watson & Kolmogorov-Smirnov & Shapiro Wilk \\
IRS & 0.670 & $0.200^{*}$ & 0.450 \\
GRNIM & 0.770 & $0.200^{*}$ & 0.384 \\
\hline
\end{tabular}

Source: Researcher, 2021

\section{Research findings}

\subsection{Descriptive statistics}

Interest rate spread and gross margin overall mean scores are more or less the same (interest rate spread mean of $10.2 \%$ against gross margin of $10.3 \%$ ) suggesting that bank loans form a significant part of banks assets as well as sources of income. Interest rate spread is highest among large banks with a mean (SD) of 0.114(.025) closely followed by small banks at a mean (SD) of 0.112(.024) while medium banks posted the lowest mean (SD) of $0.089(.035)$. Gross margin means follow the same pattern with large banks recording the highest mean (SD) of $0.119(0.018)$, followed by small and medium banks at $0.107(0.019)$ and $0.090(0.028)$ respectively. The medium banks recorded the lowest mean (SD) for both measures at 0.089(0.035) and 0.090(0.028) for interest rate spread and gross margin respectively. Unlike the large banks which by virtue of their size can exercise dominance in 
some markets, the medium banks have to contend with competition all the time. As such they must pay a premium to mobilize deposits in order to continue their lending activities. This being the case, they also accommodate more risk in order to gain more by committing a larger percentage of their money to high yielding loans. Because of these two scenarios, their interest rate spread and gross margins are the lowest and at a single digit.

Large banks appear to influence interest spread more with their mean (SD) of 0.114(0.025) being closer to the sector mean (SD) of $0.102(0.032)$ as compared to their medium size counterparts. The small banks also have a mean (SD) of $0.111(0.024)$ which is close to sector mean (SD) though with a market share of only $8 \%$ of the sector's assets and loans (CBK, 2018), their influence may be said to be small. There is not much difference in interest rate spread mean (SD) between government and private banks at $0.106(0.018)$ and $0.102(0.034)$ respectively suggesting that interest rate spread in Kenya is driven more by bank size than bank ownership. The scenario is no different for gross margins at mean (SD) of 0.102(0.018) and 0.104(0.028) for government and private banks respectively. This is unlike in the case of Pakistan where government banks posted higher spread due to their higher proportions of government deposits which are mostly non-interest bearing (Afzal \& Mirza, 2012). The case for Kenya's banking sector is different since the privatization of formerly government-owned banks which still retain the bulk of government deposits owing to their wide branch network across the country.

The incidence of default is quite varied with bank ownership. The government owned banks recorded very high default rates with a mean (SD) of $0.185(.124)$ compared to their privately owned counterparts that had a low mean (SD) of $0.077(.073)$ as seen in table 2 below. The privately owned banks have lower liquidity ratios, an indication of their risk appetite for private lending. This appetite no doubt is encouraged by their comparatively lower default rates as seen in their lower credit risk mean. The government owned banks, none of which is in the large tier have higher liquidity ratios, a matter that may be attributed to a combination of their lower appetite for private lending due to incidences of default and the sheer small size of their capital base. Large banks reported the lowest credit risk ratios with the lowest standard deviation at a mean (SD) of 0.054(.027) meaning all the large banks generally have a better performing loans portfolio. As already pointed out, this may be attributed to their more diversified portfolio as well as better loan appraisal and administration capabilities. The medium and small banks had high means with some banks recording means as high as 0.486 and 0.305 in the medium and small banks categories respectively. Liquidity ratios generally increased towards the end of the study period in response to the capping of interest rates. On the overall, the large banks are associated with higher liquidity ratios and given their asset size, it is evident that the banks elected to invest more in treasury bills especially in the period following the capping of interest rates. Whether these high liquidity ratios could be directly related with the coincidence of lower credit risk for large banks is a matter of interest though outside the scope of the current study.

High default rates were witnessed from the period after 2011 and the trend prevailed up to the end of the study period (appendix table A 2). This is attributed to the effects of the high interest rates witnessed in 2011 to 2013 which slowed down economic activities in the country (CBK, 2018). This situation was exacerbated in subsequent years by a combination of delays in payments by public and private institutions for contracted services, enhanced asset reclassification criteria and poor weather. The period under study also saw two general elections with the period surrounding such usually marked with uncertainties that tend to slow down investments. The highest default rates were witnessed towards the end of the study period due to the slowed new loans growth after the capping of interest rates coupled with low uptake of housing and commercial units which affected debt servicing by estate developers (CBK, 2015a (CBK, 2018). The liquidity ratio was fairly stable across the years around the mean of 0.072 only rising briefly in 2012, 2014 and 2016 with reduced lending to private customers following rising interest rates and the eventual capping in 2016.

Table 2 Descriptive statistics

\begin{tabular}{lllll}
\hline & $\begin{array}{l}\text { IRS } \\
\text { Mean(SD) }\end{array}$ & $\begin{array}{l}\text { GRNIM } \\
\text { Mean(SD) }\end{array}$ & $\begin{array}{l}\text { CR } \\
\text { Mean(SD) }\end{array}$ & $\begin{array}{l}\text { LR } \\
\text { Mean(SD) }\end{array}$ \\
\hline ALL BANKS & $0.102(0.032)$ & $0.103(0.027)$ & $0.094(.091)$ & $0.072(.025)$ \\
LARGE & $0.114(0.025)$ & $0.118(0.018)$ & $0.054(.027)$ & $0.076(.023)$ \\
MEDIUM & $0.089(0.035)$ & $0.090(0.028)$ & $0.097(.106)$ & $0.068(.028)$ \\
SMALL & $0.111(0.024)$ & $0.107(0.019)$ & $0.187(.081)$ & $0.072(.021)$ \\
GOVT & $0.106(0.018)$ & $0.102(0.018)$ & $0.185(.124)$ & $0.082(.029)$ \\
PRIVATE & $0.102(0.034)$ & $0.104(0.028)$ & $0.077(.073)$ & $0.070(.024)$ \\
\hline
\end{tabular}

Source: Researcher, 2021

\subsection{Hypothesis testing}

Hypothesis testing was done through correlation and regression analysis. Table 1 carries the results of the Pearson correlation statistics. The correlations for credit risk with both interest rate spread and gross margin are negative and non-significant, an indication that credit risk doesn't have much impact on bank spread in Kenya's banking 
sector. Liquidity ratio is found to be positive and significant for both spread measures demonstrating that as the ratio of liquid assets increases, so does spread. Both results are contrary to the hypothesized outcomes and the possible reasons are discussed below.

The regression analysis for this study employed the PCSE estimator as explained earlier and table 4.22 below carries the results of the same. The overall model has predictive power $(p=0.000)$ and the variables analysed account for $27.86 \%$ of changes in interest rate spread and $22.46 \%$ of changes in gross margins of Kenya's banking sector.

The effect of credit risk on interest rate spread is positive though non-significant $(\mathrm{z}=0.12, p=0.905)$ at $p$ $<0.05$. The impact on gross margin is negative and again non-significant $(\mathrm{z}=-0.96, p=0.336)$ at $p<0.05$ respectively. The negative sign on gross margin nevertheless points to the risk mitigating effect of other incomes on credit risk. Every unit change in credit risk results in a 0.0029 units' increase in interest rate spread and 0.0259 units' reduction for gross margin. The relationship between liquidity ratio is positive and significant for both spread measures at $(\mathrm{z}=5.60, p=0.000)$ at $p<0.05$ and $(\mathrm{z}=4.58, p=0.000)$ at $p<0.05$ for interest rate spread and gross margin respectively. A unit change in liquidity ratio results to a 0.677 units' increase in interest rate spread and 0.485 units' increase in gross margin.

Table 3 Linear regression, correlated panels corrected standard errors (PCSEs)

\begin{tabular}{lllllll}
\hline & IRS & & GRNIM & \\
& Coef. & $\mathrm{z}$ & $\mathrm{P}>|\mathrm{z}|$ & Coef. & $\mathrm{z}$ & $\mathrm{P}>|\mathrm{z}|$ \\
\hline CR & .0029017 & 0.12 & 0.905 & -.0258874 & -0.96 & 0.336 \\
LR & .6774985 & 5.60 & 0.000 & .4850693 & 4.58 & 0.000 \\
\hline \multicolumn{7}{l}{} \\
\hline
\end{tabular}

Source: Researcher, 2021

We make the following conclusions regarding the hypotheses under this objective from the finding of the statistical analyses above. The relationship for credit risk was inconclusive as to the direction and magnitude as the p-values were not significant in both the correlation and regression analyses. There was evidence of a negative relationship between liquidity risk and bank spread contrary to the hypothesized relationship.

\subsection{Discussion of findings}

The foregoing analyses were carried out to measure the impact of risk on bank spread in Kenya's banking sector. The analysis employed two risk measures namely credit risk and liquidity risk. The spread measures were interest rate spread and gross margin. On the overall, credit risk as proxied by the non-performing loans ratio is high at a mean of $9.4 \%$ with some banks posting as high ratios as $48.6 \%$. The liquidity ratio mean of $7.2 \%$ had high variations between banks with the lowest posting a mean of $2.7 \%$ while the highest recorded $16.4 \%$. By their sheer size, large banks clearly have the advantage of exploiting economies of scale to afford better loan administration mechanisms and drive a large balance sheet. This is evidenced in their lower credit risk ratios and higher liquidity ratios. Government owned banks recorded higher credit risk ratios as well as liquidity ratios compared to their privately owned counterparts. The correlation and regression results were inconclusive for credit risk with nonsignificant results for both spread measures. The relationship for interest rate spread was positive but that for gross margin was negative demonstrating that incomes from non-interest sources mitigate credit risk. The relationship for liquidity ratio remained positive and significant for both spread measures in the correlation and regression analyses.

The relationship between credit risk and bank spread is based on the assumption that since loans default leads to bad debt provision costs, risk averse banks are likely to impose higher risk premium on loans in response to high default incidence thus increasing bank spread. Indeed several studies done in different countries and economic blocks have found significant positive relationship between credit risk and bank spreads (Fofack, 2016; Koffie et al., 2014; Rusuhuzwa et al., 2016). Other scholars like Ghasemi and Rostami (2015) have found a negative relationship between credit risk and interest rate spread a situation attributed to the interest reservation upon loans default which reduces interest income. In our case, the relationship for interest rate spread was positive and nonsignificant while it was negative and non-significant for gross margin in the regression analysis. Liquidity ratio, used to proxy liquidity risk is the ratio of liquid assets to deposits and measures the ability of a bank to fund its current demands for payments. Liquidity risk decreases with the increase in this ratio as banks with higher levels of liquid assets have lower chances of difficulty to make such payment. The directional signs on the correlation and regression analyses are understood in the light of this fact. Both correlation and regression analyses returned positive and significant results showing that increase in the liquidity ratio is associated with increased spread. Since higher liquidity ratios denote lower risk, it therefore means the results of these analyses are that liquidity risk has a negative association with both spread measures. Both spread measures increase and liquidity risk reduces.

According to theory, banks with high liquidity risk are forced to make emergency borrowing at high costs to cover their cash withdrawal and new loan drawdowns and indeed some studies have confirmed this to be so (Ahokpossi, 2013). Other empirical studies have found a negative association between liquidity risk and bank 
spread. Liquid assets tend to earn very little income if any at all. Though more liquid assets reduce liquidity risk, beyond a certain level, the opportunity cost of holding such low yielding assets exceeds the risk mitigation benefits. When this happens, banks are forced to charge higher rates on loans hence leading to wider margins (Koffie et al., 2014). In the case of Kenya, banks are required to work with a regulatory required liquidity ratio of $20 \%$. Throughout the period under research, the banks selected operated with an average of $38.1 \%$ with one bank posting as high a liquidity ratio as $75.3 \%$ (appendix table A 3). One of the reasons for this is that rising interest rates in Kenya tend to be signalled by rising Treasury bill rate prompting banks to shift their lending to government due to the risk free nature of such debt. This increases the value of their liquid assets. On the other hand, high interest rates tend to slow down growth of loans as customers shy away from the high cost of finance. While the risk of default is mitigated in investing in government paper, the opportunity cost of this low earning investment is then made up for by raising interest on loans and reducing interest on deposits hence the positive association between liquidity ratio and bank spread that is seen in this study. The other reason for this relationship stems from the fact that Kenya's banks depend heavily on deposits to fund their lending activities. With a large proportion of these deposits being in demand accounts, the re-finance risk is high prompting banks to impose higher risk premiums.

\section{Conclusion and recommendations}

The non- performing loans ratio was high throughout the period under review with a mean of $9.4 \%$ and the highest record of $48.6 \%$. The liquidity ratio had an overall mean of $7.2 \%$ with the highest ratio record of $16.4 \%$ and lowest at $2.7 \%$, a demonstration that there are wide variations between banks. Privately owned banks and large banks fared better comparatively in terms of the non-performing loans ratio and exposure to liquidity risk. The correlation statistics showed non-significant results for credit risk while liquidity risk was negative and significant. Liquidity risk was found to have a negative and significant effect on both interest rate spread and gross margin, a phenomenon that could be attributed to banks covering for the opportunity cost of high liquidity by imposing higher interest spread.

The Central Bank has introduced several interventions to address the issue of information asymmetry in the industry. The most current among such measures being credit reference bureaus that allow banks to access both positive and negative information about the credit standing of customers from a central point. This should enable banks make informed lending decisions thereby reducing risk of default and the resultant costs. Alongside this was the introduction of the requirement for banks to price all their loans using an annual percentage rate and quote the total cost of credit on loan contracts to enable the customer to make informed decisions in terms of cost effectiveness. To support access to this information, Central Bank, in conjunction with the Kenya Bankers' Association came up with a public website called costofcredit where customers can be able to compare the total cost of credit per product for all the banks before making a choice of where to borrow (CBK, 2018). As per CBK's Bank Supervision Report of 2018, the use of this website is still low and there is need to further publicize the same. The gains of this development may also be partly eroded by banks that still require a certain duration of account history with a customer before they can enter into a borrowing contract making it difficult for a customer to make the best choice if that choice is not their current banker especially where their financing need is immediate. There is therefore need to encourage banks to reduce or do away with this requirement by addressing the concerns they might be seeking to mitigate by the account history duration. Strengthening the depth of information available with credit reference bureaus and ensuring the information on the costofcredit website is current and complete will go a long way in addressing information asymmetry in the sector for both the customer and member banks.

The liquidity ratio which was used as the proxy for liquidity risk in this study showed a positive and significant relationship with both interest rate spread and gross margin. Given that higher liquidity ratio signifies less risk, this would therefore mean that as this risk is mitigated for the Kenyan banks through holding more assets in liquid form, the opportunity cost of this action is recovered through wide spreads. Such spread is created by reducing interest on deposits or increasing interest on loans. With the high level of demand deposits especially in the large banks, most of the banks in Kenya do not have to struggle for cheap deposits especially those that have employed technological platforms to help in deposit mobilization. The incidence of default on private loans is still quite high and especially during the period of the interest rate capping, most banks shied away from such lending preferring to lend to government instead. To ensure good margins, most banks moved away from interest-bearing deposits. Managed government spending to reduce demand by government to borrow will help direct banks back to lending to private individuals. With such eased pressure comes reduced rates on treasury bills and bonds which usually have the sequential effect of reducing lending and deposit rates hence strengthening access to finance. With easy access to finance, underfunded businesses have a chance to thrive and be able to repay their loans on schedule thereby reducing default. Banks should seek other longer-term sources of funding for their lending activities and come up with more investment products for customers with investable funds to minimize liquidity risk premiums. This study was based on annual bank data covering ten years. A similar study covering a longer period is recommended to further examine the relationship between credit and bank spreads in Kenya. 


\section{References}

Afzal, A., \& Mirza, N. (2012). Interest Rate Spreads in an emerging economy: The Case of Pakistan's Commercial Banking Sector. Economic Research, 25(4), 987-1004. https://doi.org/10.1080/1331677X.2012.11517543

Ahokpossi, C. (2013). Determinants of Bank Interest Margins in Sub-Saharan Africa (WP/13/34).

Ben Khediri, K., \& Ben-Khedhiri, H. (2011). Determinants of bank net interest margin in tunisia: A panel data model. Applied Economics Letters, 18(13), 1267-1271. https://doi.org/10.1080/13504851.2010.534052

CBK. (2015a). Bank supervision annual report 2015.

CBK. (2015b). Statistical Bulletin, December 2015. December.

CBK. (2018). $\quad$ Bank Supervision Annual Report $\quad 2018 . \quad 86$. http://www.centralbank.go.ke/downloads/bsd/annualreports/bsd2010.pdf

Fofack, A. D. (2016). The determinants of interest rate spread: Empirical evidence from the Central African economic and monetary community income. Journal of Economics and International Finance, 8(6), 66-78. https://doi.org/10.5897/JEIF2016.0759

Georgievska, Ljupka; Kabashi, Rilind; Trajkovska, Nora Manova; Mitreska, Ana; Vaskov, M. (2011). Determinants of lending interest rates and interest rate spreads (ISSN 1792-6564; Issue February). Bank of Greece Printing Works.

Gesang Raharjo, P., Budiman Hakim, D., Hayman Manurung, A., \& Maulana, T. N. (2014). The Determinant of Commercial Banks' Interest Margin in Indonesia: An Analysis of Fixed Effect Panel Regression. International Journal of Economics and Financial Issues, 4(2), 295-308. www.econjournals.com

Ghasemi, A., \& Rostami, M. (2015). Determinants of interest rate spread in banking industry. International Journal of Applied Research, 1(9).

Giordano, Luca; Lopez. (2015). Competition Versus Efficiency : What Drives Banks ' Spreads in Italian Banking System? Competition versus Efficiency: What Drives B anks '. ResearchGate, June. https://doi.org/10.2139/ssrn.2640899

Gounder, N., \& Sharma, P. (2012). Determinants of bank net interest margins in Fiji, a small island developing state. Applied Financial Economics, 22(19), 1647-1654. https://doi.org/10.1080/09603107.2012.674202

Ho, S.Y. Thomas; Saunders, A. (1981). The Determinants of Bank Interest Margins: Theory and Empirical Evidence. Journal of Financial and Quantitative Analysis, XVI(4), 581-601.

Koffie, A. N., Edder, M., \& Pineda. (2014). Determinants of Banks' Net Interest Margins in Honduras. In IMF Working Paper (Vol. 14, Issue 163). https://doi.org/10.5089/9781498317931.001

Konar, Y. (2014). Factors Explaining Net Interest Margins and Spreads in Turkish Banking Sector: Evidence from 2002 - 2013. August.

Männasoo, K. (2012). Determinants of Bank Interest Spread in Estonia. In Working Paper (1/2012; Working Paper Series, ISSN 1406-7161).

Maudos, J., \& Fernández De Guevara, J. (2004). Factors explaining the interest margin in the banking sector of the European Union. Journal of Banking and Finance, 28, 2259-2281.

Ndungu, N. S., \& Ngugi, R. W. (2000). Banking Sector Interest Rate Spread in Kenya (DP No 5; Issue 5).

Perez, P. (2011). Determinants of Interest Rate Spread in Belize.

Raharjo, P. G., Hakim, D. B., Manurung, A. H., \& Maulana, T. N. A. (2014). The Determinant of Commercial Banks ' Interest Margin in Indonesia : An Analysis of Fixed Effect Panel Regression 1. International Journal of Economics and Financial Issues, 4(2), 295-308.

Rebei, N. (2014). Determinants of Interest Rate Spreads in Solomon Islands.

Romero, Jose Pablo Barquero; Rodriguez, C. S. (2011). Determinants of interest rate spread in Costa (No. 032011; Issue 03). Central Bank of Costa Rica, Economic Research Department.

Rusuhuzwa, T. K., \& Karangwa, Mathias; Nyalihama, C. (2016). Determinants of interest rate spread in Rwanda : Empirical evidence. Issues in Business Management and Economics, 4(May), 33-40.

Ugur, A., \& Erkus, H. (2010). Determinants of the Net Interest Margins of Banks in Turkey. Journal of Economic and Social Research, 12(2), 101-118.

Valverde, C. S; Fernandez, F. R. (2007). The determinants of bank margins in European banking. Journal of Banking and Finance, 31(7), 2043-2063. https://doi.org/10.1016/j.jbankfin.2006.06.017

Were, M., \& Wambua, J. (2013). Assessing the determinants of interest rate spread of commercial banks in Kenya: An empirical investigation (WPS/01/13).

\section{APPENDIX}

Appendix tables

Table A 1 World interest rate spread

\begin{tabular}{lllllllllll}
\hline & $\mathbf{2 0 0 9}$ & $\mathbf{2 0 1 0}$ & $\mathbf{2 0 1 1}$ & $\mathbf{2 0 1 2}$ & $\mathbf{2 0 1 3}$ & $\mathbf{2 0 1 4}$ & $\mathbf{2 0 1 5}$ & $\mathbf{2 0 1 6}$ & $\mathbf{2 0 1 7}$ & $\mathbf{2 0 1 8}$ \\
\hline IRS & 5.93 & 6.028 & 6.024 & 5.836 & 5.853 & 5.715 & 5.332 & 5.716 & 5.453 & 5.504 \\
\hline
\end{tabular}

Source: World Bank Group (US) https://data.worldbank.org/indicator/FR.INR.LNDP accessed on 13/4/2021 
Table A 2 Banking sector annual growth of NPL and NPL ratio

\begin{tabular}{lllllllllll}
\hline YEAR & $\mathbf{2 0 0 9}$ & $\mathbf{2 0 1 0}$ & $\mathbf{2 0 1 1}$ & $\mathbf{2 0 1 2}$ & $\mathbf{2 0 1 3}$ & $\mathbf{2 0 1 4}$ & $\mathbf{2 0 1 5}$ & $\mathbf{2 0 1 6}$ & $\mathbf{2 0 1 7}$ & $\mathbf{2 0 1 8}$ \\
\hline NPL ratio & $15 \%$ & $11 \%$ & $9 \%$ & $10 \%$ & $12 \%$ & $12 \%$ & $15 \%$ & $20 \%$ & $23 \%$ & $25 \%$ \\
\hline
\end{tabular}

Source: CBK Bank Supervision reports and researcher's calculations

Table A 3 Statutory average liquidity ratios for commercial banks

\begin{tabular}{lllll}
\hline & Mean & Minimum & Maximum & Std. Deviation \\
\hline 2009 & .38038 & .281 & .655 & .104289 \\
2010 & .44031 & .307 & .753 & .123652 \\
2011 & .35062 & .261 & .671 & .106673 \\
2012 & .39054 & .256 & .604 & .088517 \\
2013 & .35923 & .270 & .480 & .054664 \\
2014 & .34892 & .283 & .460 & .059772 \\
2015 & .35600 & .300 & .540 & .067473 \\
2016 & .35631 & .140 & .570 & .116616 \\
2017 & .39485 & .220 & .590 & .113398 \\
2018 & .43338 & .220 & .670 & .121163 \\
\hline TOTAL & .38105 & .140 & .753 & .100551 \\
\hline
\end{tabular}

\section{Appendix figure 1 Validity tests}
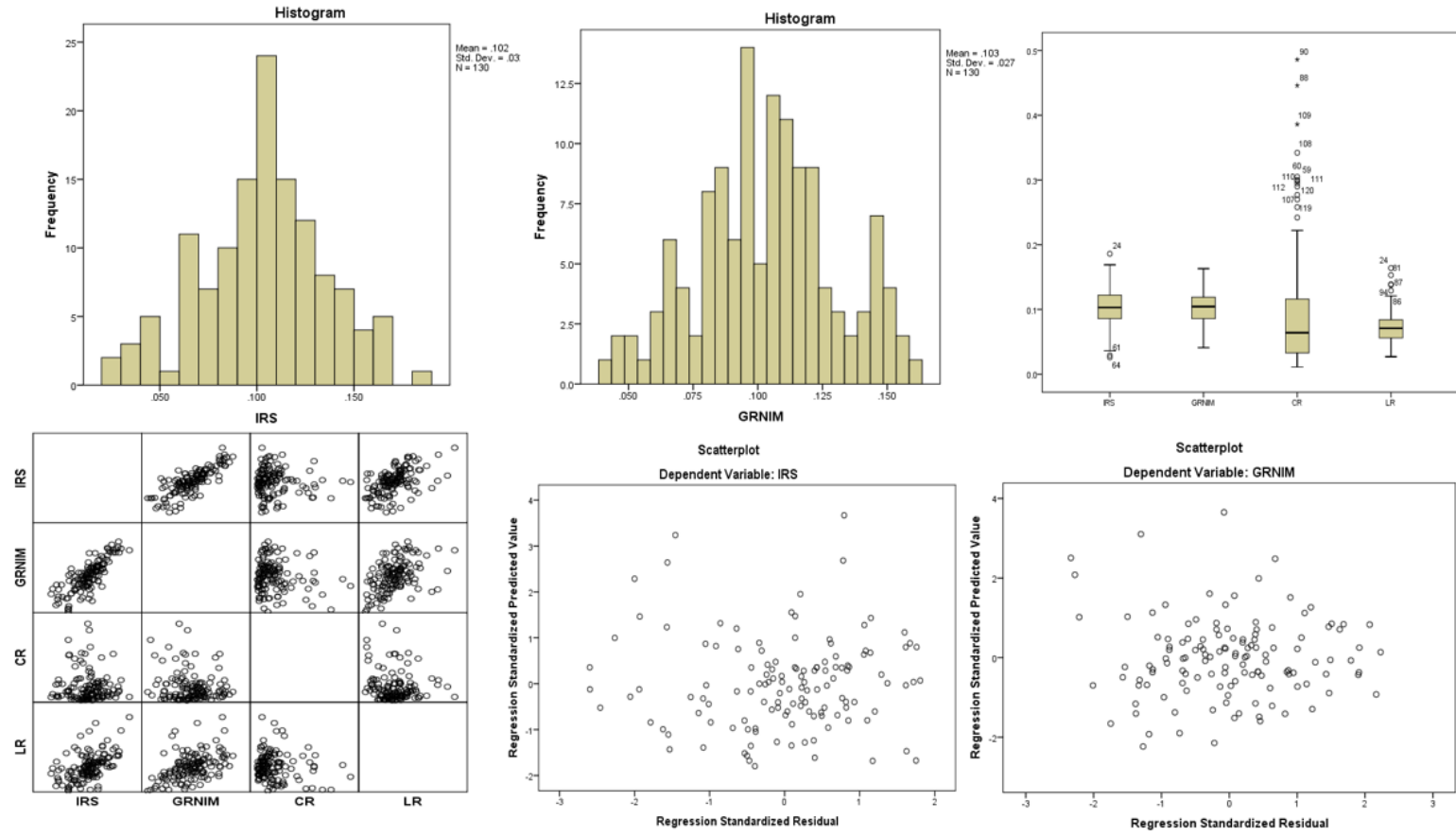